\title{
Assessing Folic Acid Awareness and its Usage for the Prevention of Neural Tube Defects Among Pregnant Women in Jos, Nigeria
}

\author{
Ajen Stephen Anzaku \\ Department of Obstetrics and Gynaecology, College of Health Sciences, Bingham University, Karu, Jos Campus, Jos, Nigeria
}

\section{A B S T R A C T}

Background: In the precent study, firm evidences indicate that folic acid supplementation during the peri-conceptional period reduces the risk of having a baby with neural tube defects. Aim: To ascertain the level of awareness about folic acid, its use during peri-conceptional period and the predictive factors of folic acid awareness among pregnant women in our setting. Subjects and Methods: Confidential, anonymous questionnaires were administered to consecutive 543 pregnant women seeking routine antenatal care at Bingham University Teaching Hospital, Jos between January and June 2012. Questions included enquiry on their demographic features, obstetric history, pregnancy intention, awareness and intake of folic acid during the peri-conceptional period, and knowledge of its natural sources. Descriptive statistics and multivariate logistic regression to identify predictive factors of folic acid awareness were then performed. Results: Out of 543 pregnant women surveyed, 64.6\% (351/543) reported that they were aware of folic acid as a vitamin supplement. However, only $7.4 \%$ (26/351) consistently took the vitamin during the protective periconceptional period. The common sources of information about folic acid were health workers (68.5\%) and the media (14.6\%). Only $26.5 \%$ (93/351) of them could correctly identify a natural source of food rich in folic acid. Multivariate logistic regression showed that maternal age $>30$ years $(P=0.01)$ and higher educational status $(P=0.001)$ were predictive factors for folic acid awareness. Conclusion: Folic acid awareness as a vitamin supplement was relatively high among the women surveyed but its intake during peri-conceptional period was worryingly low. Antenatal and Population health educational strategies and fortification of staple foods with folic acid may improve its intake among women of child-bearing age in our setting.

KEY WORDS: Awareness in pregnant women, folic acid, neural tube defects, peri-conceptional usage

\section{INTRODUCTION}

Neural tube defects (NTDs) are congenital structural anomalies of the embryonic structure that develops into the brain, spinal cord, and their surrounding structures. They are common worldwide..$^{[1-3]}$ They are serious birth defects and the second most common major congenital abnormalities occurring in about $2-3 \%$ live births. ${ }^{[4]}$ Anencephaly is incompatible with life while spina bifida is associated with varying degrees of physical and mental disabilities even after treatment. Some of these are loss of bladder and bowel function, paralysis of the lower limbs, and hydrocephalus. Furthermore, there are reports suggesting increasing cases of these disorders in our environment. ${ }^{[5,6]}$ The implications of this negative trend are the enormous physical, emotional, psychological, and financial burdens

\begin{tabular}{|l|l|}
\hline \multicolumn{2}{|c|}{ Access this article online } \\
\hline Quick Response Code & Website: \\
\hline & www.jbcrs.org \\
\cline { 2 - 2 } & \\
\hline
\end{tabular}

on the affected families, the care givers as well as the community as a whole.

However, these serious birth defects are to a large extent preventable by adequate intake of folic acid by women of the reproductive age and several studies reported that peri-conceptional supplementation of folic acid can prevent up to $50 \%$ of the cases of NTDs as well as cardiac and craniofacial abnormalities. ${ }^{[1,7,8]}$ Also, intake of folic acid in pregnancy contributes to the prevention of anaemia and peripheral neuropathy in the mother including possibly pre-term delivery. ${ }^{[9]}$ Despite wide availability of its natural food sources (green leafy vegetables, bananas, legumes), folic acid deficiency among women of reproductive age is common worldwide ${ }^{[10,11]}$ usually as a result of low-dietary intake or cooking losses. ${ }^{[10]}$

Demands for folic acid increase during pregnancy as it is required for growth and development of the fetus.

Address for correspondence Dr. Ajen Stephen Anzaku, Departments of Obstetrics and Gynaecology, Bingham University Teaching Hospital, PMB 2238, Jos, Plateau State, Nigeria. E-mail: steveanzaku@gmail.com 
Public-health approaches aimed at increasing the consumption of folic acid by women of reproductive age so as to prevent NTDs include improvement in dietary habits, fortification of staple foods and peri-conceptional use of multi-vitamin supplements containing folic acid. ${ }^{[12]}$ Daily intake of $0.4-0.5 \mathrm{mg}$ of folic acid is recommended during the peri-conceptional period, ${ }^{[12]}$ which encompasses the interval from 1 month before conception to 3 months after conception. Hence, folic acid supplementation in women in the child-bearing age, especially those with history of previous pregnancy complicated by NTDs is recommended in the peri-conceptional period to prevent these disorders. ${ }^{[13]}$

As a result of this recommendation, most developed countries came up with policies aimed at women of child-bearing age especially, those intending to become pregnant to take additional dietary and supplementary folic acid in the peri-conceptional period and most have found this to be effective in reducing incidence of NTDs. ${ }^{[14,15]}$ Despite this important outcomes on the benefits of preventing NTDs using folic acid supplementation, peri-conceptional intake of this important micronutrient remains low in several countries as many women are unaware of its benefits and the recommendations..$^{[16,17]}$

Hence, this study was undertaken to 1) assess the level of folic acid awareness among pregnant women including their knowledge of its natural sources, usefulness in preventing NTDs and peri-conceptional intake recommendation. 2) Ascertain their actual intake of the vitamin during the peri-conceptional period for the prevention of NTDs, and 3) explore the predictive factors of folic acid awareness among the pregnant Nigerian women seeking antenatal care in our health facility in Jos, Nigeria.

\section{SUBJECTS AND METHODS}

This cross-sectional study was conducted at the antenatal clinic of Bingham University Teaching Hospital, Jos, from January to July, 2012. The survey was conducted on consecutive pregnant women who presented in the clinic to register for antenatal care. A pilot study was conducted to pre-test the questionnaires and corrections were effected. Trained nurses administered the questionnaires to the subjects and where appropriate conducted face-to-face interview with them to extract the required information.

The questionnaires consisted of questions about socio-demographic variables, obstetric history, whether pregnancy was planned, awareness and sources of information about folic acid as vitamin supplement and for the prevention of NTDs. Assessment also included knowledge about its natural sources, role of folic acid in preventing NTDs, knowledge about peri-conceptional folic acid intake as a recommendation for the prevention of NTDs, actual intake of folic acid supplements during the periconceptional period, previous personal or family history of a child with NTDs and attitude towards intake of folic acid supplements to prevent NTDs in future pregnancies. Awareness in the study was defined as having "heard" or "read" about folic acid as a vitamin supplement and the peri-conceptional period as a period from 1 month before conception to 3 months after conception.

Data was analysed using SPSS software package version 16 for windows (SPSS Inc., Chicago, IL, USA). Numerical variables were expressed as mean (SD) and categorical variables expressed as percentages. Chi square test or Fisher exact test (used whenever expected cell value was $<5$ ) was used to analyse the association between categorical variables. Univariate analysis and multiple logistic regression models were carried out to determine the factors influencing awareness of folic acid as a vitamin supplement among the women. A $P<0.05$ was considered statistically significant. Ethical clearance was obtained for the study from the Health Research and Ethics Committee of Bingham University Teaching Hospital, Jos.

\section{RESULTS}

A total of 595 pregnant women were approached to participate in the study. Twenty of them declined while thirty two had incompletely filled questionnaires and were therefore, excluded from the study leaving a total of $543 / 595(91.3 \%)$ cases available for analysis.

The mean age (SD) of the women was 29.9 (4.7) years while $17.3 \%$ of them were aged 35 years and above with a range of 16-41 years. The mean gestational age at which interview was conducted was 20.5 (6.2) weeks. About $34.2 \%(186 / 543)$ of the women were nulliparous while $3.3 \%$ (18/543) were grand multiparous ( 5 or more previous deliveries). Women aged greater than 30 years were more likely to have a history of previous delivery $(P$ value $=0.001)$. Fourteen percent (76/543) and $22.2 \%(121 / 543)$ of them had previous history of at least one stillbirth and spontaneous abortion respectively. Pregnancy was planned in $60.4 \%(328 / 543)$ of the women while $39.6 \%(215 / 543)$ of the pregnancies were unplanned. Table 1 shows the demographic characteristics and parity distribution of the women.

About $64.6 \%(351 / 543)$ of the women reported that they were aware of folic acid as a reproductive health-promoting supplement (vitamin supplement). Among the total respondents, about 26.9\% (146/543) and 23.6\% (128/543) were aware of the role of folic acid in preventing NTDs and peri-conceptional recommendation of folic acid intake aimed at preventing NTDs respectively. However, among 
those that were aware of folic acid, $41.6 \%$ (146/351) of them understood that folic acid could help in preventing NTDs while $36.5 \%$ (128/351) were knowledgeable of the need to take folic acid supplements during the peri-conceptional period for the prevention of NTDs. Although, 126 (35.9\%) of the women that had knowledge of folic acid took it at some points during the peri-conceptional period, only $7.4 \%(26 / 351)$ took it consistently during the protective period to prevent NTDs. The main source of information about folic acid among the women was mainly from health workers (68.5\%) which were nurses, doctors and pharmacists. Table 2 shows the sources of information about folic acid among the study population.

About 275 (50.6\%) of the women had heard of NTDs, $5.5 \%(15 / 275)$ of them had personal history of a baby with NTDs while $6.1 \%(17 / 275)$ had history of a friend and or relation's baby affected by NTDs. Among those with personal history of a baby with NTD, only $40 \%$ (6/15) of them took folic acid at some points during the peri-conceptional period to prevent a recurrence of the disorder. Assessment of their knowledge about types of natural sources of foods rich in folic acid was also carried out and surprisingly, only $26.5 \%$ of those that were aware of folic acid could correctly identify any source of food rich in folic acid (green vegetables, fruits, cereals, fish etc.,). About 84.5\% (459/543) of the women had positive attitude towards folic acid intake during the peri-conceptional period to prevent NTDs in future pregnancies.

Univariate analysis shows that having secondary or tertiary education, age greater than 30 , parity one and above, and previous personal history of a baby with NTD were associated with increased awareness about folic acid among the women [Table 3]. However, when the above factors were subjected to multivariate logistic analysis, only age greater than $30(P=0.01,95 \% \mathrm{Cl} 1.241-5.142)$ and having secondary or tertiary education $(P=0.001,95 \% \mathrm{CI}$ 2.014-15.706) were found to be independent factors that positively influenced folic acid awareness among the study population.

\section{DISCUSSION}

This study showed that $64.6 \%$ of the pregnant women were aware of folic acid as a vitamin supplement; $41.6 \%$ of these understood that folic acid contributes to the prevention of NTDs while $36.5 \%$ were knowledgeable of the recommendation for peri-conceptional folic acid intake aimed at preventing NTDs. This level of folic acid awareness is comparable to $63.2 \%$ reported from Turkey ${ }^{[8]}$ but higher than figures of $36.0 \%$ and $53.7 \%$ from China and Qatar respectively. ${ }^{[18,19]}$ However, folic acid awareness rate as high

\begin{tabular}{|c|c|c|}
\hline Features & Frequency & Percentage \\
\hline \multicolumn{3}{|l|}{ Age (years) } \\
\hline$<20$ & 9 & 1.7 \\
\hline $20-25$ & 84 & 15.5 \\
\hline $26-30$ & 204 & 37.6 \\
\hline $31-35$ & 180 & 33.1 \\
\hline$\geq 36$ & 66 & 12.1 \\
\hline Total & 543 & 100.0 \\
\hline \multicolumn{3}{|c|}{ Educational status } \\
\hline Arabic & 18 & 3.3 \\
\hline Primary & 51 & 9.4 \\
\hline Secondary & 177 & 32.6 \\
\hline Tertiary & 297 & 54.7 \\
\hline Total & 543 & 100.0 \\
\hline \multicolumn{3}{|l|}{ Religion } \\
\hline Christianity & 519 & 95.6 \\
\hline Islam & 24 & 4.4 \\
\hline Total & 543 & 100.0 \\
\hline \multicolumn{3}{|l|}{ Parity } \\
\hline 0 & 186 & 34.2 \\
\hline $1-2$ & 249 & 45.9 \\
\hline 3-4 & 90 & 16.6 \\
\hline$\geq 5$ & 18 & 3.3 \\
\hline Total & 543 & 100.0 \\
\hline
\end{tabular}

\begin{tabular}{lcc}
\hline \multicolumn{3}{c}{ Table 2: Sources of information about folic acid } \\
\hline Sources of information & Frequency & Percentage \\
\hline Health workers & 295 & 68.5 \\
Electronic media & 32 & 7.4 \\
Print media & 31 & 7.2 \\
Internet & 10 & 2.3 \\
Friends & 44 & 10.2 \\
Relations & 19 & 4.4 \\
Total & 431 & 100.0 \\
\hline
\end{tabular}

Some of the women had two or more sources of information

\begin{tabular}{|c|c|c|c|c|}
\hline \multirow[t]{2}{*}{ Factors } & \multicolumn{2}{|c|}{$\begin{array}{c}\text { Awareness about } \\
\text { folic acid }\end{array}$} & \multirow[t]{2}{*}{$\begin{array}{l}\text { Odd } \\
\text { ratios }\end{array}$} & \multirow[t]{2}{*}{$P$ values } \\
\hline & Yes & No & & \\
\hline \multicolumn{5}{|l|}{ Age group } \\
\hline$>30$ & 192 & 54 & 3.086 & $0.001 * *$ \\
\hline$\leq 30$ & 159 & 138 & & \\
\hline \multicolumn{5}{|l|}{ Literacy level } \\
\hline Secondary and tertiary & 333 & 141 & 6.691 & $<0.0001^{* *}$ \\
\hline Arabic and primary & 18 & 51 & & \\
\hline \multicolumn{5}{|l|}{ Parity } \\
\hline $1-6$ & 252 & 105 & 2.109 & $0.02 * *$ \\
\hline 0 & 99 & 87 & & \\
\hline \multicolumn{5}{|l|}{ Planning of pregnancy } \\
\hline Planned pregnancy & 216 & 111 & 1.168 & 0.24 \\
\hline Unplanned pregnancy & 135 & 81 & & \\
\hline \multicolumn{5}{|l|}{ History of a baby with NTD } \\
\hline Yes & 30 & 0 & 9.044 & $\ddagger_{0.015^{* *}}$ \\
\hline No & 321 & 192 & & \\
\hline \multicolumn{5}{|c|}{ History of a relative/friend's baby with NTD } \\
\hline Yes & 30 & 3 & 5.888 & $0.1^{\ddagger}$ \\
\hline No & 321 & 189 & & \\
\hline
\end{tabular}

as $76.1 \%$ and $89.0 \%$ were noted in Thailand and Australia. ${ }^{[20,21]}$ This relatively high-rate of awareness among the study population could be as a result of previous intake of folic acid supplements during past pregnancies as majority of them 
were of parity one and above. This is supported by the fact that the most common source of information about folic acid was through health workers. Folic acid is usually prescribed routinely in addition to Iron supplements during pregnancy in our environment mainly for the prevention of anaemia.

Among the entire study population, $26.9 \%$ were aware of the role of folic acid in the prevention of NTDs while $23.6 \%$ knew about peri-conceptional recommendation for the intake of the vitamin aimed at preventing NTDs. This low-level of awareness about the role of folic acid in the prevention of NTDs is comparable to $25.5 \%$ and $24.1 \%$ reported from Ido-Ekiti and Port Harcourt in Nigeria respectively. ${ }^{[22,23]}$ This low-awareness of the role of folic acid in the prevention of NTDs, despite the fact that about $87.3 \%$ of the women in our study had at least secondary education emphasizes the need for public-health education targeting women of reproductive age on the importance of folic acid as a reproductive health-promoting supplement in our environment.

Despite the availability of scientific evidence on the prevention of NTDs by folic acid supplementation and its recommendation by health authorities, only $7.4 \%$ of the women that were aware of folic acid actually took it consistently during the peri-conceptional period with the aim of preventing NTDs. Low-peri-conceptional intake of folic acid among women was also noted in Spain (6.9\%) and Ireland $(2.7 \%)^{[17,24]}$ but in contrast to the findings in developed nations such as Canada and USA where $25-45 \%$ of women take folic acid during the peri-conceptional period. ${ }^{[25,26]}$ This worryingly low-intake rate of folic acid supplements during this protective period even among women with previous or family history of a baby with NTDs despite the awareness rate may be attributed to the high-rate of unplanned pregnancies among the pregnant women.

The low-peri-conceptional intake of folic acid may also be attributable to late presentation for antenatal care leading to late prescription of the vitamin for women during pregnancy by the health workers as most of our women commence antenatal care late in pregnancy as noted in this study ( $20.5 \pm 6.2$ weeks). This finding of late booking (4.6 months) for antenatal care was also noted among women that presented with babies affected by NTDs in a neurosurgical unit in South-western, Nigeria ${ }^{[27]}$ Furthermore, peri-conceptional care for women that are planning to get pregnant is virtually non-existent in our environment where folic acid can be prescribed particularly for those with high-risk of NTDs. This is a pointer for more efforts by the public-health sector in enlightening the general populace on the importance of peri-conceptional folic acid intake by women of child-bearing age so as to effect a positive attitudinal change among them.
Among the women, only $26.5 \%$ could correctly identify a natural source of food rich in folic acid. Low-knowledge about natural sources of folic acid was also noted among women in Turkey and Thailand where $39.3 \%$ and $32.4 \%$ were reported respectively. ${ }^{[20,28]}$ The prevalence of NTDs seems to be increasing in our environment. ${ }^{[5,6]}$ Though, the reason for this trend is unknown, it may be as a result of the ignorance among our women of the rich natural food sources of the vitamin and or loss of the vitamin as a result of over cooking of the food sources. This poor knowledge underscores the need for the fortification of staple foods such as flour, sugar and salt with folic acid with the aim of increasing its intake among women of reproductive age in our setting. This strategy has been proven to be effective in reducing incidences of NTDs in developed countries. ${ }^{[14,15]}$

The main source of information about folic acid among the women was through the health workers. This is in contrast to the findings from elsewhere where the media was the main source of information about folic acid. ${ }^{[17,20]}$ This may not be unconnected to the fact that most of the women were multiparous and so were in one-time or the other in contact with these health workers and or were prescribed the vitamin supplement during their previous pregnancies. More efforts are therefore, needed to promote awareness about folic acid through the media because of its wider coverage among the population. Hence, young females will also benefit and use the knowledge positively when married and this will contribute to the overall increase in the correct use of folic acid for the primary prevention of NTDs among women of reproductive age in our environment.

The study showed that age greater than 30 years and higher educational status (secondary and tertiary levels) were independent factors associated with folic acid awareness among the study population. This is in contrast to the findings in other studies where older age group was associated with folic acid unawareness. ${ }^{[28,29]}$ Older women in our setting are likely to have taken folic acid in their previous pregnancies as most of them were at least primiparous or of higher parity $(P$ value $=0.001)$ and this probably influenced their awareness about folic acid. However, other studies ${ }^{[28,20]}$ also supported the positive correlation between increasing level of education with folic acid awareness as noted in this study.

This study has some limitations. One of these is the fact that it was conducted in a Teaching hospital setting and the result may not be a true reflection of the actual situation in the general community. Another limitation of the study is recall bias as all responses were self-reported and this may affect the outcomes of the study.

In conclusion, although, awareness about folic acid as a vitamin supplements was relatively high among the pregnant 
women, their knowledge about its importance in preventing NTDs and periconceptional intake recommendation were low. More disturbing was their abysmally low-knowledge about its natural food sources and actual intake of the vitamin during the protective peri-conceptional period.

Antenatal and population health promotion programs aimed at enlightening women of child-bearing age about the importance of folic acid, its rich natural sources and the need for peri-conceptional intake of the vitamin so as to promote intake of folic acid supplements among them is therefore recommended. Furthermore, fortification of stable foods with this vitamin will help in increasing folic acid intake among women, which at the end will contribute to the prevention or reduction in the incidence of NTDs among our populace.

\section{ACKNOWLEDGMENT}

I sincerely appreciate Mrs. Olasumbo Ojegbile and Mrs. Dinatu Bako of the antenatal clinic for their contribution in administering the questionnaires to the women and conducting face-to-face interviews with some of them.

\section{REFERENCES}

1. Folic acid for the prevention of neural tube defects. American Academy of Pediatrics. Committee on Genetics. Pediatrics 1999;104:325-7.

2. Audu LI, Shehu BB, Thom-Manuel IJ, Mairami AB. Open neural tube defects at the National Hospital Abuja: An analysis of clinical patterns and neonatal outcomes. Niger J Paediatr 2004;31:131-6.

3. Shawky RM, Sadik DI. Congenital malformations prevalent among Egyptian children and associated risk factors. Egypt J Med Hum Genet 2011;12:69-78.

4. Toriello HV, Professional Practice and Guidelines Committee, American College of Medical Genetics. Folic acid and neural tube defects. Genet Med 2005;7:283-4.

5. Ugwu RO, Eneh AU, Oruamabo RS. Neural tube defects in a university teaching hospital in southern Nigeria: Trends and outcome. Niger J Med 2007;16:368-71.

6. Bello M, Abubakar AM, Akuhwa RT, Yahaya SJ, Adamu S, Mava Y. Neural tube defects: Epidemiologic factors, clinical presentation and outcome in North Eastern Nigeria. Sahel Med J 2008;11:34-7.

7. Watkins ML. The efficacy of folic acid prophylaxis for the prevention of neural tube defects. Mental Retard Dev Disabil Research Rev 1998;4:282-90.

8. Finnell RH, Shaw GM, Lammer EJ, Brandl KL, Carmichael SL, Rosenquist TH. Gene-nutrient interactions: Importance of folates and retinoids during early embryogenesis. Toxicol Appl Pharmacol 2004;198:75-85.

9. Greenberg JA, Bell SJ, Guan Y, Yu YH. Folic Acid supplementation and pregnancy: More than just neural tube defect prevention. Rev Obstet Gynecol 2011;4:52-9.

10. Haidar J, Melaku D, Pobocik RS. Folate deficiency in women of reproductive age in nine administrative regions of Ethiopia: An emerging public health problem. S Afr J Clin Nutr 2010;23:132-7.

11. McLean E, de Benoist B, Allen LH. Review of the magnitude of folate and vitamin B12 deficiencies worldwide. Food Nutr Bull 2008;29:S38-51.

12. Ekweagwu E, Agwu AE, Madukwe E. The role of micronutrients in child health: A review of literature. Afr J Biotechnol 2008;7:3804-10.

13. ACOG Practice bulletin. Clinical management guidelines for Obstetricians-Gynecologists, No 44, July 2003. Obstet Gynecol 2003;102:203-13.

14. De Wals P, Tairou F, Van Allen MI, Uh SH, Lowry RB, Sibbald B, et al. Reduction in neural-tube defects after folic acid fortification in Canada. N Engl J Med 2007;357:135-42.

15. Williams LJ, Mai CT, Edmonds LD. Prevalence of spina bifida and anencephaly before and after mandatory folic acid fortification in the United States. Teratology 2006;66:33-9.

16. Abdulrazzaq YM, Al-Gazali LI, Bener A, Hossein M, Verghese M, Dawodu A, et al. Folic acid awareness and intake survey in the United Arab Emirates. Reprod Toxicol 2003;17:171-6.

17. Coll O, Pisa S, Palacio M, Quintó L, Cararach V. Awareness of the use of folic acid to prevent neural tube defects in a Mediterranean area. Eur J Obstet Gynecol Reprod Biol 2004;115:173-7.

18. Ren A, Zhang L, Li Z, Hao L, Tian Y, Li Z. Awareness and use of folic acid, and blood folate concentrations among pregnant women in northern China - An area with a high prevalence of neural tube defects. Reprod Toxicol 2006;22:431-6.

19. Bener A, Al Maadid MG, Al-Bast DA, Al-Marri S. Maternal knowledge, attitude and practice on folic acid intake among Arabian Qatari women. Reprod Toxicol 2006;21:21-5.

20. Nawapun K, Phupong V. Awareness of the benefits of folic acid and prevalence of the use of folic acid supplements to prevent neural tube defects among Thai women. Arch Gynecol Obstet 2007;276:53-7.

21. Oddy WH, Miller M, Payne JM, Serna P, Bower CI. Awareness and consumption of folate-fortified foods by women of childbearing age in Western Australia. Public Health Nutr 2007;10:989-95.

22. Rabiu TB, Tiamiyu LO, Awoyinka BS. Awareness of spina bifida and periconceptional use of folic acid among pregnant women in a developing economy. Childs Nerv Syst 2012;28:2115-9.

23. Eghwrudjakpor PO, Amadi CE, Amusan EO. Evaluation of the level of awareness of the role of folic acid in the prevention of neural tube defects amongst women of reproductive age in a tertiary health institution. Niger J Med 2011;20:207-12.

24. Sayers GM, Hughes N, Scallan E, Johnson Z. A survey of knowledge and use of folic acid among women of child-bearing age in Dublin. J Public Health Med 1997;19:328-32.

25. Morin P, De Wals P, St-Cyr-Tribble D, Niyonsenga T, Payette H. Pregnancy planning: A determinant of folic acid supplements use for the primary prevention of neural tube defects. Can J Public Health 2002;93:259-63.

26. Kloeblen AS. Folate knowledge, intake from fortified grain products, and periconceptional supplementation patterns of a sample of low-income pregnant women according to the Health Belief Model. J Am Diet Assoc 1999;99:33-8.

27. Adeleye AO, Dairo MD, Olowookere KG. Central nervous system congenital malformations in a developing country: Issues and challenges against their prevention. Childs Nerv Syst 2010;26:919-24.

28. Baykan Z, Oztürk A, Poyrazoğlu S, Gün I. Awareness, knowledge, and use of folic acid among women: A study from Turkey. Arch Gynecol Obstet 2011;283:1249-53.

29. Sharp GF, Naylor LA, Cai J, Hyder ML, Chandra P, Guillory VJ. Assessing awareness, knowledge and use of folic acid in Kansas women between the ages of 18 and 44 years. Matern Child Health J 2009;13:814-21.

How to cite this article: Anzaku AS. Assessing folic acid awareness and its usage for the prevention of neural tube defects among pregnant women in Jos, Nigeria. J Basic Clin Reprod Sci 2013;2:13-7.

Source of Support: Nil, Conflict of Interest: None declared 